\title{
Role of N-Butyl 2 Cyanoacrylate for Flap Adhesion to Avoid Packing in Septoplasty- A Pilot Study
}

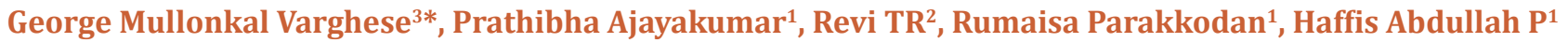 \\ and Vishnupriya Padmakumar ${ }^{1}$
}

${ }^{1} J u n i o r$ residents, Jubilee Mission Medical College Hospital and Research Institute, India

${ }^{2}$ Senior Anesthesiologist, Jubilee Mission Medical College Hospital and Research Institute, India

${ }^{3}$ Professor, Jubilee Mission Medical College Hospital and Research Institute, India

Submission: October 10, 2017; Published: October 26, 2017

*Corresponding author: George Mullonkal Varghese, Professor, Kerala University of Health Sciences, Jubilee Mission Medical College Hospital and Research Institute, Mullonkal house, East fort, Thrissur, Kerala, India, Tel: 9447333653; Email: drgeorgemv@gmail.com

Abstract

Aim: How to avoid a packing following the Septoplasty was the research problem. There are certain established ways like keeping a nasal splint, use of nasal clips or even suturing the septal flaps. But each has its own problems like cost, difficulty in execution due to problems like nonvisualisation through a narrow tunnel like are when stiches are put. The hypothesis was to find out the effectiveness of N-Butyl Cyanoacrylate in producing a firm flap adhesion after a routine Septoplasty.

Materials \& Methods: This is a retrospective, non-comparative pilot study comprising of 25 patients for whom Septoplasty was done for various indications, mainly an obstructed nose. We used NOSE score for evaluating the patients before and after the surgery. It is a questionnaire to assess quality of life of patients with nasal pathology from the American Academy of Otolaryngology.

Results: In all the patients, there were very evident changes in the breathing capacity of the nose in the operated individuals. The NOSE score improved to 100 in all patients except in a boy of 7 years for whom the postoperative score was 10 and for the rest 24 patients had complete relief of the symptom of nasal obstruction. The allergic rhinitis group had to continue antihistamines. There were no complications except a small synechiae in a single patient.

Conclusion: N -Butyl 2 Cyanoacrylate is a tissue adhesive used in many Surgical specialties safely. It is F D A approved, and an effective tool in getting firm flap adhesion in Septoplasty surgery, thereby avoiding a pack inside the nose which is not only uncomfortable to the patient, but also dangerous in risky patients, and avoids a painful pack removal.

Keywords: N butyl 2 cyanoacrylate; Deviated nasal septum; Septoplasty; Flap adhesion; No pack technique of Septoplasty

Abbreviations: (n-BCA): n-butylcyanoacrylate; EVOH: Ethylvinyl Alcohol Copolymer; NBCA: n-butyl cyanoacrylate

\section{Introduction}

Septoplasty is a frequently done operation for symptomatic deviation of nasal septum, in many of the ENT departments, either alone or in combination with other surgeries inside the nose. Sometimes it may be combined with other procedures like FESS, synechiae release, AC polypectomy, Adenoidectomy, or turbinoplasty also. As the last step in the operation, nasal cavity is often packed with medicated gauze, or splinted or rarely clips are used for stabilization and to promote adhesion between the mucosal flaps of the septum. Most often a nasal pack is the choice for the surgeon as it is a simple procedure compared to splints and clips which are costly and have to be kept in the nose for variable time. This causes problems like, a blocked nose till the pack is removed, dry mouth, watering of eyes, and severe pain during removal of the pack blocked ears, headache, difficulty in swallowing, hypoxia, etc. Rarely, it can cause toxic shock syndrome also.

Many Surgeons avoid packing by putting quilting sutures endonasally to avoid a pack, but at the same time approximatesmucosal flaps effectively, preventing a hematoma. Though this is of immense help to the patient, the problem with this method of mucosal approximation is that the extra time and difficulty of putting the sutures trans-nasally. One method of avoiding this problem is to use synthetic tissue adhesives like $\mathrm{N}$ butyl 2 cyanoacrylate in between the flaps and keep a small pack 


\section{Global Journal of Otolaryngology}

for a few minutes to avoid leakage and to get a tight pressure. Then the pack can be removed and thereby the patient can have a patent airway immediately after surgery. Another advantage is that, he/she can be discharged one the next day itself or the same day after a few hours of observation. The tissue adhesive $\mathrm{N}$-Butyl Cyanoacrylate is used in various Surgical specialities also as seen below.

This is a FDA approved [1-16] synthetic tissue adhesive belonging to the second generation of cyanoacrylates [2-4] Cyanoacrylates have been used in most surgical disciplines like abdominal surgery (to seal wound of the liver) gynecology, maxillofacial surgery and neurosurgery, orthopedic surgery, plastic surgery (to close skin wounds), urogenital surgery, vascular surgery, thoracic surgery [3] even though it was initially used for closure of skin wounds [4]. But $\mathrm{N}$ butyl 2 cyanoacrylate has got certain advantages like their ability to rapidly form a flexible bond, act as an occlusive protective dressing, decrease inflammation, and reduce follow-up care and medical costs. In terms of wound closure strength, the tensile strength of cyanoacrylates is stronger than that of fibrin tissue adhesives [5]

\section{Materials and Methods}

This is a retrospective, non-comparative pilot study comprising of 25 patients for whom Septoplasty was done for various indications, mainly an obstructed nose or as a preparation for Ear surgery, in Jubilee Mission Medical College Hospital, Thrissur, South India during a period of 6 months' time. Informed consent was taken from every patient. All the patients were informed of the study and all of them gracefully accepted the suggestion since they need not to have a blocked nose post operatively and can get discharged one day before the usual pattern. This study was conducted in accordance with the ethical principles stated in the Declaration of Helsinki [6] and with the approval of Institutional review board and Ethical committee (Tables $1 \& 2$ ).

Table 1.

\begin{tabular}{|c|c|c|c|c|c|c|}
\hline Group 1 & Group 2 & Group3 & Group 4 & Group 5 & Group 6 & Total \\
\hline \multirow{2}{*}{ Age less than 10 } & $\begin{array}{c}\text { Age between } \\
10-20\end{array}$ & $\begin{array}{c}\text { Age between } \\
21-30\end{array}$ & $\begin{array}{c}\text { Age, between } \\
31-40\end{array}$ & $\begin{array}{c}\text { Age, between } \\
41-50\end{array}$ & $\begin{array}{c}\text { Bgetween } \\
51-60\end{array}$ & Males-18 \\
\hline \multirow{2}{*}{ 1-male } & $\begin{array}{c}2 \text { males, } \\
1 \text { female }\end{array}$ & $\begin{array}{c}12 \\
8 \text { males } \\
4 \text { females }\end{array}$ & $\begin{array}{c}3 \text { males } \\
2 \text { females }\end{array}$ & 2 males & 2 Fales & Females-7 \\
\hline
\end{tabular}

Table 2: Case distribution.

\begin{tabular}{|c|c|c|c|}
\hline Septoplasty alone & Septoplasty \& adenoidectomy & Septoplasty\& MMA & Septoplasty \& A C polypectomy \\
\hline 21 & 1 & 1 & 2 \\
\hline
\end{tabular}

Table 3: Disease distribution.

\begin{tabular}{|c|c|}
\hline D N S Alone & 17 \\
\hline DNS \&Nasal allergy & 7 \\
\hline DNS \& Maxillary Sinusitis & 1 \\
\hline
\end{tabular}

The Anaesthesiologists also were happy because the risk of developing any complication in the post-operative phase is comparatively low. The age varied from 7 yeas to 57 years, mostly being male. All the operations were done by a single Surgeon. 18 patients were males and 7 patients, female. Age and sex distribution is given in table 1 , the type of surgery in table 2 and the disease in table 3 . All the patients were of ASA1or 2 risk only (American Society of Anesthesiologists). Exclusion criteria were hypertension, diabetes, cases were bleeding is anticipated like patients on antiplatelet drugs or those who are having coagulation disorders. Revision surgery was not a contraindication (Table 4).

Table 4: Nasal obstruction symptom evaluation scale (NOSE Scale).

\begin{tabular}{|c|c|c|c|c|c|c|}
\hline Problem & $\mathbf{0}$ & $\mathbf{1}$ & $\mathbf{2}$ & $\mathbf{3}$ & $\mathbf{4}$ & Final score \\
\hline & Not a problem-0 & $\begin{array}{c}\text { Very mild } \\
\text { problem-1 }\end{array}$ & $\begin{array}{c}\text { Moderate } \\
\text { problem-2 }\end{array}$ & $\begin{array}{c}\text { Fairly bad } \\
\text { problem-3 }\end{array}$ & $\begin{array}{c}\text { Severe } \\
\text { problem-4 }\end{array}$ & \\
\hline $\begin{array}{c}\text { Nasal congestion } \\
\text { or stuffiness }\end{array}$ & & & & & & \\
\hline $\begin{array}{c}\text { Nasal blockage or } \\
\text { obstruction }\end{array}$ & & & & & & \\
\hline $\begin{array}{c}\text { Trouble breathing } \\
\text { through my nose }\end{array}$ & & & & & & \\
\hline Trouble sleeping & & & & & \\
\hline
\end{tabular}




\begin{tabular}{|c|l|l|l|l|l|}
\hline $\begin{array}{c}\text { Unable to get } \\
\text { enough air } \\
\text { through }\end{array}$ & & & & & \\
\hline $\begin{array}{c}\text { my nose during } \\
\text { exercise or } \\
\text { exertion }\end{array}$ & & & & & \\
\hline
\end{tabular}

Septoplasty is performed using standard technique under G. A. An initial infiltration with 2 percent xylocaine containing $1 / 1000$ adrenaline is given 5 to 10 minutes before the surgery and the nose was packed with surface anaesthetic agent 4 percent xylocaine diluted with Oxymetazolineor adrenaline. Then the usual septoplasty procedure is carried out and care is taken to avoid any septal tear. The Anaesthesiologist keeps the mean arterial pressure around $65 \mathrm{~m}$.m of mercury. Now the synthetic tissue adhesive $\mathrm{N}$ butyl 2 cyanoacrylate is squeezed form the container into the area between the flaps from posterior to the anterior part of the inter-mucosal area. Then a small pack soaked with Oxymetazoline nasal drops is put to exert pressure on the flaps and also to avoid leakage in the event of an unavoidable tear of the flap in acutely deviated cases. After 2 or 3 minutes, it can be removed. At the end of the operation, a single quilting suture starting from the roomy side to the narrow side and from there back to the roomy side is put and then the final sutures of the incision site are closed [7].

A. Protocol: After getting the written informed consent from the patient, the demographic and clinical details of the patients are collected by the junior authors. The Nasal Symptom Evaluation Scoresare also calculated by them.

B. Post -operative instructions: Since no pack is put, precautions to prevent a hematoma are taken. The patient is given a head up position and asked not to blow the nose. Injectable antibiotics are given along with decongestant nasal drops and saline nasal drops for the prevention of small clots. Analgesics are routinely used antihistamines only in patients who are having allergic rhinitis. If necessary, laxatives are given to prevent straining on stools. Often the patient is kept in the ward for a single day for observation.

We use NOSE scale by Stewart M G et al. [7] for evaluating the patients before and after the surgery. It is a questionnaire to assess quality of life of patients with nasal pathology from the American Academy of Otolaryngology. Patients are asked to circle the response closest to their current symptoms. Then the circled responses are added up. Multiply that number by 5 to base the scale out of a possible score of 100 for analysis

\section{Results}

In all the patients, there were very evident changes in the breathing capacity of the nose in the operated individuals. The NOSE score improved to 100 in all patients except in a boy of 7 years for whom the postoperative score was 10 and for the rest 24 patients had complete relief of the symptom of nasal obstruction. The allergic rhinitis group had to continue antihistamines. There was no hematoma, infection or any other problems. One patient had a small synechiae, probably as a result of leakage of the adhesive, through a unilateral inevitable, flap tear to the deviated side in the initial series, following which the nose was packed temporarily to avoid leakage and to exert pressure even though the adhesive makes tight bondage within a minute's time. The following chart shows the results (Figure 1).

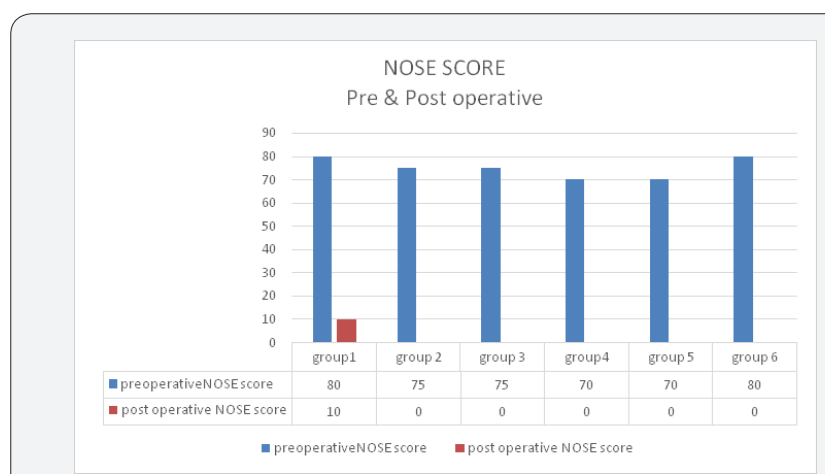

Figure 1: Nasal obstruction symptom evaluation scale (NOSE Scale).

\section{Discussion}

Michael Vaiman et al. [8] used fibrin glue, as a convenient and simple method to avoid nasal packing. In 2003, Payem Danshread et al. [9] reported that fibrin glue is an effective method of approximating septal flaps.

\section{Uses of $\mathbf{N}$ Acetyl 2 Cyanoacrylate in Human tissue- review of literature}

Cyanoacrylates adhesives have been suggested for a variety of adhesive purposes including glues and surgical adhesives. The polymer will adhere to the skin for a period of about 3 to 7 days after which time it sloughs off. By this time, the healing process is sufficiently complete that there is little danger of wound reopening. Barley et al in Oct. 19, 1993 got the patent for using Butyl 2 cyanoacrylate [10]. Butyl and isobutyl cyanoacrylates are noncarcinogenic and non-toxic in living organisms unlike the ethyl and methyl cyanoacrylatecompounds. Initially it was a method for closing the separated skin sections of a saturable wound of the skin.

In mucosal wounds: In a study by C B Giray et al. [11] named 'Clinical and electron microscope comparison of silk sutures and n-butyl-2-cyanoacrylate in human mucosa' that the product has antimicrobial activity. Bacteriostatic effects against gram-positive microorganisms of n-butyl-2-cyanoacrylate have 
been also reported. It is not toxic, non-mutagenic and noncarcinogenic. The tissue adhesive is used in mucosal surgeries of cleft lip and palate [12]. In Maxillofacial surgery, on the side of the frenulum, it was proved that the use of cyanoacrylate glue has resulted in less postoperative inflammation and good clinical and histological healing when compared to the silk sutures [13].

Nasal Septal surgery: Irfan O zyazgan, \& Onurkan_Idacl, concluded in their article named, 'A New Method That Uses Cyanoacrylate Tissue Adhesive to Fill Scoring Incisions in Septal Cartilage Correction' that, Cyanoacrylate is an effective, instant, safe method of treatment in correcting deviated septal cartilage with scoring incisions and filling the gaps of the incisions [14]. But it is not used in the adhesion of the flaps

Use in Ophthalmology: Cyanoacrylate adhesives were first applied in ophthalmology in the mid-1960s in treatment of corneal dehiscence and are widely used for closure of aqueous leaks following trauma, spontaneous corneal melting and surgery. They have also been reported to be valuable in the management of retinal detachment [13] in securing orbital implants [14] for procuring temporary tarsorrhaphy and for removal of intraocular lenses [16] Cyanoacrylate adhesives have also been used to obtain temporary punctal occlusion [15].

Use in embolization - Head and Neck Surgery, Interventional Radiology: Cyanoacrylates are the main liquid adhesives used in the vascular system and have an important role in managing vascular abnormalities, especially arteriovenous malformations. Vascular occlusion results as these agents polymerize on exposure to the ions in blood. A description of the properties, biologic interactions, techniques of use, and indications for acrylic embolization in the peripheral circulation is especially pertinent at this time because of the recent approval of n-butyl cyanoacrylate by the United States Food and Drug Administration [16].

Preoperative embolization of vascular tumors reduces bleeding, and the need for transfusion, as well as improves the visualization of intraoperative surgical field. Embolic agents include polyvinyl alcohol, transacryl microspheres, liquid n-butylcyanoacrylate (n-BCA), ethylvinyl alcohol copolymer (EVOH), and microcoils [17]. The two-main liquid embolic agents used in the embolisation of Juvenile Nasopharyngeal Angiofibroma are Onyx and n-butyl cyanoacrylate (NBCA). The benefits of Onyx over NBCA have been well described and are primarily due to the slower precipitation properties of Onyx [18]. In a study, prior to surgical excision the author's devascularized low-flow vascular lesions of upper aero-digestive system on the operation table by injection of N-butyl cyanoacrylate into lesion under strict fluoroscopy control [19].

In many years of cyanoacrylate use in humans involving thousands of patients, not one documented case of carcinogenesis has been reported. Histologic studies of tissue surfaces coated with cyanoacrylic have revealed a wide spectrum of local toxicity, with intensity of reaction inversely proportional to the length of the alkyl side chain NBCA, while causing significant vascular injury, is not different from IBCA in this respect. It is, however, demonstrably more reactive: it is polymerized more easily and quickly than IBCA and the polymerization speed is affected much less by the addition of oil. When the need for such fast polymerizing embolic agents is compelling, NBCA could be directly substituted for IBCA, requiring little adjustment in clinical technique [20] Materials used to embolize and occlude the offending vessel are gel foam, polyvinyl alcohol (PVA), steel or tantalum coils and NBCA (N-butyl-cyanoacrylate) glue of size not less than 150- 200 microns, best results being obtained with particle size of 250-350 microns [21].

Comparison between the complications of patients undergoing nasal septoplasty, with or without nasal packing showed lesser complications with pack less Septoplasty $[22,23]$. We also had a similar result without any incidence of hematoma or post-operative bleeding or residual deviation or perforation except for a single case of a small synechiae which could be easily released So far, the use of $\mathrm{N}$-Butyl2 Cyanoacrylate in the Septoplasty flap adhesion has been described only in rabbits. The authors stated that in their rabbit septoplasty model, N-Butyl cyanoacrylate appeared to be an effective nasal tissue adhesive with low complication rates [24]. We hope ours is the first study in humans of similar nature with a follow up of 6 months with very good efficacy and without having any hematoma, infection except for a single case of small synechiae in the initial series.

\section{Conclusion}

$\mathrm{N}$-Butyl 2 Cyanoacrylate is a tissue adhesive used in many surgical specialties safely. It is F D A approved, and an effective tool in getting firm flap adhesion in Septoplasty surgery, thereby avoiding a pack inside the nose which is not only uncomfortable to the patient in many ways, but also dangerous in risky patients, and avoids a painful pack removal.

\section{References}

1. Spotnitz, William D (2014) Fibrin sealant: the only approved hemostat, sealant, and adhesive-a laboratory and clinical perspective. ISRN surgery 2014.

2. Arjunan, Karthikeyan, Balasubramanian Thiagarajan, Seethalaksmi Narashiman (2012) Role of tissue adhesive in otorhinolaryngology. Otolaryngology online journal 2(3): 1-16.

3. Donkerwolcke, Monique, F Burny, Dominique Muster (1998) Tissues and bone adhesives-historical aspects. Biomaterials 19(16): 14611466.

4. Qureshi A (1997) n-Butyl cyanoacrylate adhesive for skin closure of abdominal wounds: preliminary results. Annals of the Royal College of Surgeons of England 79(6): 414.

5. Mobley, Steven Ross, John Hilinski, Dean M Toriumi (2002) Surgical tissue adhesives." Facial Plastic Surgery Clinics 10(2): 147-154.

6. World Medical Association (2008) Declaration of Helsinki. Ethical principles for medical research involving human subjects. 
7. Stewart, Michael G (2008) Development and validation of the Nasal Obstruction Symptom Evaluation (NOSE) scale 1. Otolaryngology-Head and Neck Surgery 130(2): 157-163.

8. M Vaiman, E Eviatar, S Segal (2008) The use of fibrin glue as hemostatic in endonasal operations: a prospective, randomized study. 40(4): 185188 .

9. Daneshrad, Payam, Gregory Y Chin, Dale H Rice (2003) Fibrin glue prevents complications of septal surgery: findings in a series of 100 patients. Ear, nose \& throat journal 82(3): 196.

10. Barley, Linda M, J Royce Renfrow, Michael Byram (1993) Methods for treating suturable wounds by use of sutures and cyanoacrylate adhesives. U.S. Patent No. 5(254): 132.

11. Giray CB (1997) Clinical and electron microscope comparison of silk sutures and n-butyl-2-cyanoacrylate in human musosa. Australian dental journal 42(4): 255-258.

12. Gosman, Amanda A (2000) Cleft Lip and Palate Part 2: Surgical Management.

13. Kumar, M Suresh (2013) Comparison between Silk Sutures and Cyanoacrylate Adhesive in Human Mucosa-A Clinical and Histological Study. Journal of international oral health: JIOH 5(5): 95.

14. Özyazgan, İrfan, Onurkan Idacı (2011) A new method that uses cyanoacrylate tissue adhesive to fill scoring incisions in septal cartilage correction. The Laryngoscope 121(6): 1164-1172.

15. Diamond, Jeremy P (1995) Cannalicular occlusion with cyanoacrylate adhesive: a new treatment for the dry eye. Eye 9(1): 126-129.

16. Pollak, Jeffrey S, Robert I White (2001) The use of cyanoacrylate adhesives in peripheral embolization. Journal of Vascular and Interventional Radiology 12(8): 907-913.

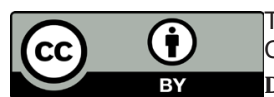

This work is licensed under Creative Commons Attribution 4.0 License

DOI: $10.19080 /$ GJ0.2017.11.555810
17. Thongrong, Cattleya (2013) Control of bleeding in endoscopic skull base surgery: current concepts to improve hemostasis. ISRN surgery 2013.

18. Elhammady, Mohamed Samy (2011) Preoperative embolization of juvenile nasopharyngeal angiofibromas: transarterial versus direct tumoral puncture. World neurosurgery 76(3): 328-334.

19. Tyagi, Isha, Rajan Syal, Amit Goyal (2006) Management of low-flow vascular malformations of upper aero digestive system-role of $\mathrm{N}$-butyl cyanoacrylate in peroperative devascularization. British Journal of Oral and Maxillofacial Surgery 44(2): 152-156.

20. Brothers MF (1989) n-Butyl 2-cyanoacrylate- substitute for IBCA in interventional neuroradiology: histopathologic and polymerization time studies. American Journal of Neuroradiology 10(4): 777-786.

21. Poduval, Jayita (2000) Bilateral Sphenopalatine Artery Embolisation in Panfacial fractures- a case report.

22. Iqbal, Moghira (2008) Nasal packing after septoplasty: a randomized comparison of packing versus no packing in 88 patients. Ear, Nose \& Throat Journal 87(11): 624 .

23. Naghibzadeh, Bijan, Ali Asghar Peyvandi, Ghazal Naghibzadeh (2011) Does post septoplasty nasal packing reduce complications? Acta Medica Iranica 49(1): 9.

24. Aksoy F (2010) Use of N-butyl cyanoacrylate in nasal septoplasty: histopathological evaluation using rabbit nasal septum model. The Journal of Laryngology \& Otology 124(7): 53-758.

\section{Your next submission with Juniper Publishers will reach you the below assets}

- Quality Editorial service

- Swift Peer Review

- Reprints availability

- E-prints Service

- Manuscript Podcast for convenient understanding

- Global attainment for your research

- Manuscript accessibility in different formats

( Pdf, E-pub, Full Text, Audio)

- Unceasing customer service

Track the below URL for one-step submission https://juniperpublishers.com/online-submission.php 